\title{
Risk model in stage IBI-IIB cervical cancer with positive node after radical hysterectomy
}

This article was published in the following Dove Press journal:

OncoTargets and Therapy

27 May 2016

Number of times this article has been viewed

\section{Zhilan Chen, ${ }^{1,2, *}$ Kecheng Huang, ${ }^{1} *$ Zhiyong Lu, ${ }^{1,3}$ Song Deng, ${ }^{1,4}$ Jiaqiang Xiong,' Jia Huang,' Xiong Li, ${ }^{5}$ Fangxu Tang,' Zhihao Wang, ${ }^{6}$ Haiying Sun,' Lin Wang,' Shasha Zhou,' Xiaoli Wang,' Yao Jia,' Ting Hu,' Juan Gui,' Dongyi Wan,' Ding Ma,' Shuang Li,' Shixuan Wang'}

'Department of Obstetrics and Gynecology, Tongji Hospital, Tongji Medical College, Huazhong University of Science and Techonology, Wuhan, ${ }^{2}$ Department of Obstetrics and Gynecology, Wuhan General Hospital of Guangzhou Military Command, Wuhan, ${ }^{3}$ Hubei Key Laboratory of Embryonic Stem Cell Research, Tai-He Hospital, Hubei University of Medicine, Shiyan, Hubei, ${ }^{4}$ Department of Obstetrics and Gynecology, University Hospital of Hubei University for Nationalities, Enshi, Hubei, ${ }^{5}$ Department of Obstetrics and Gynecology, Wuhan Central Hospital, Wuhan, ${ }^{6}$ Department of Pathology and Pathophysiology, Key Laboratory of Ministry of Education of China for Neurological Disorders, Huazhong University of Science and Techonology, Wuhan, ${ }^{7}$ Department of Obstetrics and Gynecology, Renmin Hospital, Wuhan University, Wuhan, People's Republic of China

*These authors contributed equally to this work
Correspondence: Shuang Li;

Shixuan Wang

Department of Gynecology \& Obstetrics, Tongji Hospital, Tongji Medical College, Huazhong University of Science and Technology, 1095 Jiefang Anv Wuhan, Hubei 430030, People's Republic of China

Tel +86278366 3078

Fax +86 2783663078 Email lee5190008@I26.com; sxwang2012@hotmail.com
Abstract: The purpose of this study was to identify risk factors in patients with surgically treated node-positive IB1-IIB cervical cancer and to establish a risk model for disease-free survival (DFS) and overall survival (OS). A total of 170 patients who underwent radical hysterectomy and bilateral pelvic lymphadenectomy as primary treatment for node-positive International Federation of Gynaecology and Obstetrics (FIGO) stage IB1-IIB cervical cancer from January 2002 to December 2008 were retrospectively analyzed. Five published risk models were evaluated in this population. The variables, including common iliac lymph node metastasis and parametrial invasion, were independent predictors of outcome in a multivariate analysis using a Cox regression model. Three distinct prognostic groups (low, intermediate, and high risk) were defined using these variables. Five-year DFS rates for the low-, intermediate-, and high-risk groups were $73.7 \%, 60.0 \%$, and $25.0 \%$, respectively $(P<0.001)$, and 5-year OS rates were $81.9 \%, 42.8 \%$, and $25.0 \%$, respectively $(P<0.001)$. The risk model derived in this study provides a novel means for assessing prognosis of patients with node-positive stage IB1-IIB cervical cancer. Future study will focus on external validation of the model and refinement of the risk scoring systems by adding new biologic markers.

Keywords: cervical cancer, risk model, lymph node metastasis, disease-free survival, overall survival

\section{Introduction}

Cervical carcinoma is one of the most common causes of cancer death in women across the world. ${ }^{1,2}$ Experts estimated that there were 527,600 new patients and 265,700 deaths across the world in $2012 .^{3}$ In the USA, $>12,000$ women are diagnosed every year with invasive cervical carcinoma and $>220,000$ women are living with the disease. ${ }^{4}$ Outside of the USA, the prevalence of cervical cancer is more frequent. In some areas of Europe and Asia, also of the People's Republic of China, ${ }^{5-7}$ radical surgery is indicated for patients with early cervical cancer. Surgery not only removes the disease but also provides accurate pathologic staging information, and the pathologic staging information facilitates clinicians to target adjuvant therapy.

Although retroperitoneal lymph node status is not included in the International Federation of Gynaecology and Obstetrics (FIGO) staging system, it is an important determinant of treatment, especially to design a radiation treatment plan. ${ }^{8-11}$ The positive pelvic node rate in stage IB-IIB is reported to be $15 \%-31 \% .{ }^{11}$ Five-year survival rates in patients with lymph node metastasis (LNM) vary greatly and has been declared to range from $30 \%$ to $60 \%$. This discrepancy may mainly result from the inclusion of a relative large group of patients with a varying extent of disease spread. ${ }^{12,13}$ Currently, patients with LNM receive mainly adjuvant concurrent chemoradiotherapy (CCRT) without evaluation of the risk factors. The recommendations made when pelvic LNM are found remain controversial. 
Models that predict disease-free survival (DFS) in patients with high-risk cervical cancer are useful tools in patient management, while studies involving systemic evaluation of the clinicopathologic variables related to the prognosis for positive pelvic node are scarce. After surgery, an assessment combining the pathological factors with clinical factors makes it possible to predict long-term survival such as recurrence and survival. ${ }^{12,13}$ Recently, to improve the predictive accuracy of a single clinicopathologic variable, several risk models have been built, and the risk models integrate the main clinical and pathological variables related to prognosis. ${ }^{14-20}$

This study aimed to 1) identify the prognostic factors in patients with surgically treated node-positive IB1-IIB cervical carcinoma, 2) establish a risk model for DFS rates, and 3 ) assess the prognostic performance of five published risk models in our patients.

\section{Materials and methods Patients}

The patients were selected from the database from January 2002 to December 2008 (https://clinicaltrials.gov; NCT01267851). This study was approved by the Ethics Committee at Tongji Medical College, HUST, and informed consent was given by each patient. This study included patients who met the following criteria: patient's age was between 20 and 69 years; patients had FIGO IB-IIB cervical cancer diagnosed by at least two clinical gynecologists from 2002 to 2008; patients had only squamous, adenocarcinoma, or adenosquamous histology; and patients who received primary radical surgical treatment consisting of radical hysterectomy, pelvic lymphadenectomy, and oophorectomy and were found to have pelvic LNM. Exclusion criteria included the following: 1) patients with small-cell neuroendocrine carcinoma and cervical sarcoma, 2) patients with other severe comorbidities, 3) patients with psychiatric disease, and 4) patients who received radiotherapy or CCRT before surgery. Therefore, only 170 patients fulfilled all the criteria, and the data employed in this study were from a total of 2,811 patients.

\section{Follow-up study}

DFS was defined as the time from the first day of assignment until the date of first relapse or death (regardless of cause). ${ }^{21,22}$ Monitoring comprised pelvic physical examination and vaginal cytology examination and magnetic resonance imaging (MRI) or computed tomography (CT) scan of the pelvic cavity; abdomen and chest X-ray examinations were carried out every 6 months for the first 2 years and once a year thereafter.

\section{Statistical analysis}

DFS is defined as "the time interval from surgery to the first recurrence or death, regardless of any cause". ${ }^{21,22}$ Those patients who were alive together with no recurrence were censored at the last medical contact. Log-rank function was used for the overall survival (OS) and DFS comparisons. A Cox model was used for multiple regression analysis to verify whether clinical variables and pathological response variables predict OS and DFS. Before the starting of multiple analysis, variables included in our model were first screened by univariate analysis $(P \leq 0.1)$, a method that removes unimportant variables; consequently, the method ensures a more manageable set of variables. These variables can then be analyzed by multivariate regression; they were retained in the multivariate regression if their associated multivariate $P$-values were $<0.05$ or they were necessary for the model. ${ }^{23-25}$ The statistical analyses were carried out using IBM SPSS 19.0. $P<0.05$ was considered to be statistically significant.

\section{Results}

\section{Patient data}

Among a total of 2,811 women with FIGO IB1-IIB cervical cancer, 170 women were included in the study. Baseline clinical characteristics of the 170 women are described in Table 1. The table shows that the median value of women's age was 42 years (range: 25-66). The median number of pelvic LNMs was 2.00 (range: 1-15). During our follow-up, 55 cancer recurrences and 42 cancer deaths were identified. The 5-year DFS rates were $65 \%$, and 10 -year DFS rates were $52 \%$, whereas the 5 -year OS rates were $71 \%$ and 10 -year OS rates were $55 \%$. Information regarding the location of recurrence is not available in the database and therefore was not analyzed.

\section{Univariate Cox regression for recurrence}

Both presenting clinical variables and pathological variables were used to assess the risk factors for patient outcomes after radical hysterectomy. In univariate Cox analysis for recurrence, common iliac LNM $(P<0.001)$, FIGO stage $(P=0.02)$, parametrial involvement $(P=0.002)$, and the number of positive nodes $(P=0.02)$ were significantly associated with DFS rate (Table S1). 
Table I Demographic and clinical characteristics of patients $(n=170)$

\begin{tabular}{|c|c|c|}
\hline \multirow[t]{2}{*}{ Characteristics } & \multicolumn{2}{|c|}{ Patients } \\
\hline & $\mathbf{N}$ & $\%$ \\
\hline \multicolumn{3}{|c|}{ Age at diagnosis (years) } \\
\hline$<30$ & 7 & 4.1 \\
\hline $30-39$ & 64 & 37.6 \\
\hline $40-49$ & 63 & 37.1 \\
\hline $50-59$ & 29 & I7.I \\
\hline $60-69$ & 7 & 4.1 \\
\hline \multicolumn{3}{|l|}{ Parity } \\
\hline$<2$ & 76 & 44.7 \\
\hline$\geq 2$ & 85 & 50.0 \\
\hline Unknown & 9 & 5.3 \\
\hline \multicolumn{3}{|l|}{ Histology } \\
\hline Squamous & 145 & 85.3 \\
\hline Adenocarcinoma & 19 & 11.2 \\
\hline Adenosquamous & 6 & 3.5 \\
\hline \multicolumn{3}{|l|}{ Grade } \\
\hline I & 18 & 10.6 \\
\hline 2 & 90 & 52.9 \\
\hline 3 & 62 & 36.5 \\
\hline \multicolumn{3}{|l|}{ Tumor size } \\
\hline$<4 \mathrm{~cm}$ & 122 & 71.8 \\
\hline$\geq 4 \mathrm{~cm}$ & 48 & 28.2 \\
\hline \multicolumn{3}{|c|}{ Number of positive lymph nodes } \\
\hline I & 66 & 38.8 \\
\hline 2 & 42 & 24.7 \\
\hline 3 & 29 & I7.| \\
\hline 4 & 12 & 7.1 \\
\hline$\geq 5$ & 21 & 12.4 \\
\hline \multicolumn{3}{|c|}{ Bilaterality of lymph node metastasis } \\
\hline Unilateral & 99 & 58.2 \\
\hline Bilateral & 71 & 41.8 \\
\hline \multicolumn{3}{|c|}{ Common iliac lymph node metastasis } \\
\hline No & 145 & 85.3 \\
\hline Yes & 25 & 14.7 \\
\hline \multicolumn{3}{|l|}{ FIGO stage } \\
\hline$|\mathrm{B}|$ & 76 & 44.7 \\
\hline IB2 & 29 & 17.1 \\
\hline IIA & 49 & 28.9 \\
\hline $\mathrm{IIB}$ & 16 & 9.4 \\
\hline \multicolumn{3}{|c|}{ Lymph-vascular space invasion } \\
\hline No & 124 & 72.9 \\
\hline Yes & 46 & 27.1 \\
\hline \multicolumn{3}{|l|}{ Vaginal margin } \\
\hline Negative & 161 & 94.7 \\
\hline Positive & 9 & 5.3 \\
\hline \multicolumn{3}{|l|}{ Parametrial infiltration } \\
\hline No & 152 & 89.4 \\
\hline Yes & 18 & 10.6 \\
\hline \multicolumn{3}{|l|}{ Corpus invasion } \\
\hline No & 154 & 90.6 \\
\hline Yes & 16 & 9.4 \\
\hline \multicolumn{3}{|c|}{ Deep stromal invasion } \\
\hline No & 72 & 42.4 \\
\hline Yes & 98 & 57.6 \\
\hline
\end{tabular}

Abbreviation: FIGO, International Federation of Gynaecology and Obstetrics.

\section{Development and validation of the risk model based on scoring system}

The multivariate Cox model, with both clinical and pathological variables included as potential risk factors, revealed that common iliac LNM (hazard ratio $[\mathrm{HR}]=3.18 ; P<0.001$ ) and parametrial involvement $(\mathrm{HR}=2.74 ; P=0.001)$ were the only two variables significantly correlated with DFS (Table S2). No significant interactions were observed between the two variables retained in the model. The last but not the least, because HRs for the two variables were both of similar magnitude, binary indicators such as 0 or 1 were used to present the status of common iliac LNM and parametrial involvement (Table 2). ${ }^{26}$

Overall risk score was then generated by adding together the points listed in Table 3. For the risk model, three groups of women with scores of 0-2 were identified, and the scores were associated with decreasing DFS rate (Table 3; Figure 1). According to these variables and scores, the patients were classified as following: 1) lowrisk group ( $\operatorname{score}=0, n=131$ ), women without any of the two risk factors; 2) intermediate-risk group ( $\mathrm{n}=35$ ), women with one of the two risk factors; or 3 ) highrisk group ( $\operatorname{score}=2, n=4$ ), women with two risk factors. In this study, $77.06 \%$ of patients were classified as low risk, and $22.94 \%$ of the patients were classified as high or intermediate risk. Compared with the low-risk group, the rate of cancer recurrence was much higher in both the high- $(\mathrm{HR}=7.38 ; P=0.001)$ and intermediate- $(\mathrm{HR}=3.21$; $P<0.001$ ) risk groups (Table 2). The 5-year DFS rates in the three groups were $73.7 \%, 60.0 \%$, and $25.0 \%$, respectively (Figure 1). Kaplan-Meier curves according to risk group and DFS and OS rates are shown in Figure 1. The 5 -year OS rates in the three groups were $81.9 \%, 42.8 \%$, and $25.0 \%$, respectively (Figure 1).

A multivariable Cox analysis was then performed to assess if the risk score system was valid in evaluating the OS rate by using clinical and pathological variables as candidate

Table 2 Factors associated with DFS and OS after multivariate Cox regression after including the risk model as a covariate $(n=170)$

\begin{tabular}{|c|c|c|c|c|c|}
\hline \multirow[t]{2}{*}{ Variables } & \multirow{2}{*}{$\begin{array}{l}\text { No of } \\
\text { patients }\end{array}$} & \multicolumn{2}{|c|}{ DFS } & \multicolumn{2}{|l|}{ OS } \\
\hline & & HR & $P$-value & HR & $P$-value \\
\hline \multicolumn{6}{|c|}{ Our risk model (score) } \\
\hline 0 & $13 \mid$ & 1 & & 1 & \\
\hline 1 & 35 & 3.21 & $<0.001$ & 3.04 & 0.001 \\
\hline 2 & 4 & 7.38 & 0.001 & 14.52 & $<0.001$ \\
\hline
\end{tabular}

Abbreviations: DFS, disease-free survival; OS, overall survival; $\mathrm{HR}$, hazards ratio. 
Table 3 Prognostic risk models

\begin{tabular}{ll}
\hline Factors & DFS model \\
\cline { 2 - 2 } & Scores \\
\hline Parametrial involvement & $+\mathrm{I}$ \\
Common iliac lymph node metastasis & $+\mathrm{I}$ \\
Risk groups & Points \\
Low & 0 \\
Medium & $\mathrm{I}$ \\
High & 2 \\
\hline
\end{tabular}

Abbreviation: DFS, disease-free survival.

factors. Moreover, compared with the low-risk group, the OS rate was significantly higher in the high- $(\mathrm{HR}=14.52$; $P<0.001)$ and intermediate- $(\mathrm{HR}=3.04 ; P=0.001)$ risk groups (Table 2).

\section{Validation of published models}

In addition, we searched PubMed for reports on risk models of long-term survival in surgically treated, node positive, early patients with cervical cancer since 1989 . The search consisted of both $\mathrm{MeSH}$ and keyword terms related to the identification of prognostic variables and stratification of risk groups. Only studies published in English language were included. In particular, six risk models for surgically treated node-positive cervical cancer were identified. One model did not categorize the patients into risk groups. The remaining five models were confirmed and included in our study. Table S3 depicts the data used for external validation. The models categorized the patients with cervical cancer into several risk groups. All the studies are described in Table S4.

ROC curves were used to evaluate the discrimination of the models for recurrences and OS. Our new score model (area under the curve $[\mathrm{AUC}]=0.668$ for disease recurrences and 0.667 for OS) has comparative discrimination with Alverez et al, ${ }^{20}$ Lai et al, ${ }^{18}$ Aoki et al, ${ }^{15}$ Samlal et al, ${ }^{17}$ and Park et $\mathrm{al}^{14}$ (AUC $=0.609,0.642,0.646,0.564$, and 0.575 for disease recurrences; $0.600,0.630,0.662,0.564$, and 0.575 for OS, respectively) (Figure S1).

\section{Discussion}

The current study analyzed the clinicopathologic data from 170 patients with FIGO IB1-IIB cervical cancer with LNM treated by radical surgery. After multivariate analysis, survival was influenced by common iliac lymph node status and parametrial involvement. Our findings are in accordance with the results showing that the location of LNM and parametrial tumor spread are strongly correlated with poor prognosis of cervical cancer. ${ }^{27}$

The anatomic location of LNM has been considered to be a predictor for DFS. Most of the studies reported that extensive nodal metastasis including metastasis to the nodes in or beyond the region of the common iliac vessels is a poor prognostic nodal characteristic. Several studies have reported poorer survival in patients with para-aortic lymph node involvement. ${ }^{8,13,28} \mathrm{We}$ found common iliac node involvement
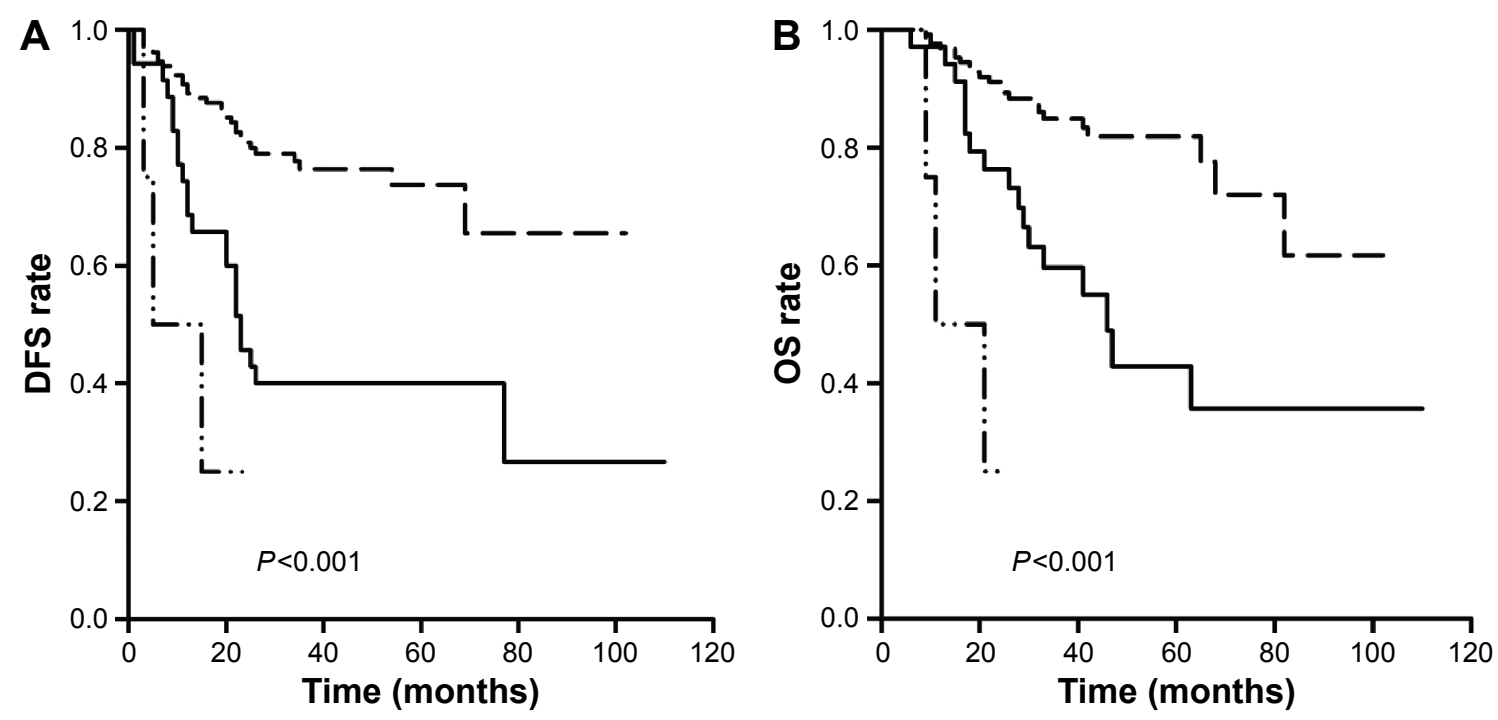

- LR group $\longrightarrow$ IR group - - - HR group

Figure I Kaplan-Meier analysis of DFS and OS in the risk groups.

Notes: DFS rates among the risk groups showed statistically significant differences using Log Rank test (A). OS rates among the risk groups showed statistically significant differences using Log Rank test (B). $P<0.05$ was considered to be significant.

Abbreviations: DFS, disease-free survival; OS, overall survival; LR, low risk; HR, high risk; IR, intermediate risk. 
is a risk factor in multivariate Cox model, as para-aortic lymphadenectomy was not performed in all patients.

Data from previous multivariate Cox model also indicate that the involvement of parametria is a prognostic factor, ${ }^{27}$ and our results are consistent with the previous finding. The incidence of parametrial involvement has been reported to be from $6 \%$ to $31 \%$, and in our study it is $10.6 \%$. Parametrial involvement was also strongly associated with other high-risk factors such as LNM, which was also reported by other scholars. ${ }^{29}$ Compared to patients without parametrial involvement, patients with parametrial involvement were approximately seven times more likely to have positive pelvic nodes and $\sim 12$ times more likely to have positive para-aortic nodes. ${ }^{27}$ Nevertheless, parametrial involvement was revealed to be related with a low survival rate in most of the published risk models. ${ }^{14,15,17,18}$ Lymph vascular space invasion is also an important prognostic factor, ${ }^{30}$ but it was not entered into multivariate Cox model in our study; this was probably due to the nature of this study, in which only patients with positive nodes were included. For the risk factors such as histology and FIGO stage, similar results were observed in this study.

Furthermore, we tried to determine whether the existing models are still valid in our patients. Table S4 presents a review of these analyses. Only the models of Aoki et $\mathrm{al}^{15}$ and Lai et $\mathrm{al}^{16}$ exactly fit our population. The poor performance of a model probably results from the disparity between the patients for which the model was designed and the patients employed for external validation. First, almost each risk model combined a particular set of risk factors. The risk factors selected for building the risk model is an important cause for its poor performance at another population. Second, the guidelines for postsurgery adjuvant therapy differed between the studies.

The study included an adequate sample size and had sufficient statistical power for the main outcomes. However, there were quite a few limitations. There may be recall bias due to the retrospective nature of the study. Our model did not integrate biologic makers associated with cancer progression and survival; ${ }^{31,32}$ in the future, we will add biomarkers into our new studies. Previous studies also investigated the differences between open radical surgery, laparoscopic radical surgery, and nerve sparing laparoscopic radical surgery, ${ }^{33-37}$ but our study did not research on this, as the data were not available at the moment and laparoscopic radical surgery showed survival rate comparable to that of radical surgery. ${ }^{34,38,39}$ In addition, new surgery type, such as radical trachelectomy reported by Park et al, ${ }^{14}$ should also be carefully investigated in our medical center.

\section{Conclusion}

In conclusion, we have built a prognostic risk model by integrating currently available clinicopathologic variables in women with IB1-IIB cervical cancer. Using our point-scoring risk model, patients can be easily classified as low-, intermediate- and high-risk groups for DFS rates by integrating currently available variables; the risk model was also valid in assessing the OS rates. The risk model can be taken into account by doctors when selecting primary treatment strategy for patients with cervical cancer. Meanwhile, prospective randomized controlled trials are needed to validate the risk models and to explore the benefits of postsurgery adjuvant treatment for the intermediate- and high-risk groups.

\section{Acknowledgments}

This research was supported by the grant from International S\&T Corporation Program of China (No 2013DFA31400), Program for New Century Excellent Talents in University (No NECT-12-0646), the Foundation of China (973 Program No 2009CB521808), the National Natural Science Foundation of China (Nos 81370469, 81302264, 81201639, $81300453,81072132,81372781,81071663,81370469$, $81230038,81230052,30973472,81001151,81071663$, 30973205, 30973184, 81172464, 81101964), and National Major Science and Technology Project (No 2009ZX09103739). We would like to thank Ms Yunping Lu for her kind help and Professor Miao for his inspiration and encouragement.

\section{Disclosure}

The authors report no conflicts of interest in this work.

\section{References}

1. Ye J, Yin L, Xie P, et al. Antiproliferative effects and molecular mechanisms of troglitazone in human cervical cancer in vitro. Onco Targets Ther. 2015;8:1211-1218.

2. Peralta-Zaragoza O, Bermudez-Morales VH, Pérez-Plasencia C, Salazar-León J, Gómez-Cerón C, Madrid-Marina V. Targeted treatments for cervical cancer: a review. Onco Targets Ther. 2012;5: 315-328.

3. Torre LA, Bray F, Siegel RL, Ferlay J, Lortet-Tieulent J, Jemal A. Global cancer statistics, 2012. CA Cancer J Clin. 2015;65(2):87-108.

4. Nie SX, Gao CQ. Health behaviors and quality of life in Chinese survivors of cervical cancer: a retrospective study. Onco Targets Ther. 2014;7:627-632.

5. Benedetti-Panici P, Greggi S, Colombo A, et al. Neoadjuvant chemotherapy and radical surgery versus exclusive radiotherapy in locally advanced squamous cell cervical cancer: results from the Italian multicenter randomized study. J Clin Oncol. 2002;20(1): 179-188.

6. Landoni F, Maneo A, Colombo A, et al. Randomised study of radical surgery versus radiotherapy for stage Ib-IIa cervical cancer. Lancet. 1997;350(9077):535-540. 
7. Chen L, Zhang F, Sheng XG, Zhang SQ. Decreased pretreatment lymphocyte/monocyte ratio is associated with poor prognosis in stage Ib1-IIa cervical cancer patients who undergo radical surgery. Onco Targets Ther. 2015;8:1355-1362.

8. Gouy S, Morice P, Narducci F, et al. Prospective multicenter study evaluating the survival of patients with locally advanced cervical cancer undergoing laparoscopic para-aortic lymphadenectomy before chemoradiotherapy in the era of positron emission tomography imaging. J Clin Oncol. 2013;31(24):3026-3033.

9. Gouy S, Morice P, Narducci F, et al. Nodal-staging surgery for locally advanced cervical cancer in the era of PET. Lancet Oncol. 2012;13(5): e212-e220.

10. Lécuru F, Mathevet P, Querleu D, et al. Bilateral negative sentinel nodes accurately predict absence of lymph node metastasis in early cervical cancer: results of the SENTICOL study. J Clin Oncol. 2011;29(13): $1686-1691$

11. Macdonald OK, Chen J, Dodson M, Lee CM, Gaffney DK. Prognostic significance of histology and positive lymph node involvement following radical hysterectomy in carcinoma of the cervix. Am J Clin Oncol. 2009;32(4):411-416.

12. Fleming ND, Frumovitz M, Schmeler KM, et al. Significance of lymph node ratio in defining risk category in node-positive early stage cervical cancer. Gynecol Oncol. 2015;136(1):48-53.

13. Ditto A, Martinelli F, Lo Vullo S, et al. The role of lymphadenectomy in cervical cancer patients: the significance of the number and the status of lymph nodes removed in 526 cases treated in a single institution. Ann Surg Oncol. 2013;20(12):3948-3954.

14. Park JY, Kim DY, Kim JH, Kim YM, Kim YT, Nam JH. Further stratification of risk groups in patients with lymph node metastasis after radical hysterectomy for early-stage cervical cancer. Gynecol Oncol. 2010;117(1):53-58.

15. Aoki Y, Sasaki M, Watanabe M, et al. High-risk group in node-positive patients with stage IB, IIA, and IIB cervical carcinoma after radical hysterectomy and postoperative pelvic irradiation. Gynecol Oncol. 2000;77(2):305-309.

16. Lai CH, Hong JH, Hsueh S, et al. Preoperative prognostic variables and the impact of postoperative adjuvant therapy on the outcomes of stage IB or II cervical carcinoma patients with or without pelvic lymph node metastases: an analysis of 891 cases. Cancer. 1999;85(7):1537-1546.

17. Samlal RA, van der Velden J, Schilthuis MS, et al. Identification of high-risk groups among node-positive patients with stage IB and IIA cervical carcinoma. Gynecol Oncol. 1997;64(3):463-467.

18. Lai CH, Chang HC, Chang TC, Hsueh S, Tang SG. Prognostic factors and impacts of adjuvant therapy in early-stage cervical carcinoma with pelvic node metastases. Gynecol Oncol. 1993;51(3):390-396.

19. Delgado G, Bundy B, Zaino R, Sevin BU, Creasman WT, Major F. Prospective surgical-pathological study of disease-free interval in patients with stage IB squamous cell carcinoma of the cervix: a Gynecologic Oncology Group study. Gynecol Oncol. 1990;38(3):352-357.

20. Alvarez RD, Soong SJ, Kinney WK, et al. Identification of prognostic factors and risk groups in patients found to have nodal metastasis at the time of radical hysterectomy for early-stage squamous carcinoma of the cervix. Gynecol Oncol. 1989;35(2):130-135

21. Diéras V, Fumoleau P, Romieu G, et al. Randomized parallel study of doxorubicin plus paclitaxel and doxorubicin plus cyclophosphamide as neoadjuvant treatment of patients with breast cancer. $J$ Clin Oncol. 2004;22(24):4958-4965.

22. Buda A, Fossati R, Colombo N, et al. Randomized trial of neoadjuvant chemotherapy comparing paclitaxel, ifosfamide, and cisplatin with ifosfamide and cisplatin followed by radical surgery in patients with locally advanced squamous cell cervical carcinoma: the SNAP01 (Studio Neo-Adjuvante Portio) Italian Collaborative Study. J Clin Oncol. 2005;23(18):4137-4145.
23. George SL. Identification and assessment of prognostic factors. Semin Oncol. 1988;15(5):462-471.

24. Sanoff HK, Sargent DJ, Campbell ME, et al. Five-year data and prognostic factor analysis of oxaliplatin and irinotecan combinations for advanced colorectal cancer: N9741. J Clin Oncol. 2008;26(35): $5721-5727$.

25. Klastersky J, Paesmans M, Rubenstein EB, et al. The multinational association for supportive care in cancer risk index: a multinational scoring system for identifying low-risk febrile neutropenic cancer patients. J Clin Oncol. 2000;18(16):3038-3051.

26. Jeruss JS, Mittendorf EA, Tucker SL, et al. Combined use of clinical and pathologic staging variables to define outcomes for breast cancer patients treated with neoadjuvant therapy. J Clin Oncol. 2008;26(2): 246-252.

27. Wright JD, Grigsby PW, Brooks R, et al. Utility of parametrectomy for early stage cervical cancer treated with radical hysterectomy. Cancer. 2007;110(6):1281-1286.

28. Grigsby PW, Siegel BA, Dehdashti F. Lymph node staging by positron emission tomography in patients with carcinoma of the cervix. $J$ Clin Oncol. 2001;19(17):3745-3749.

29. Martinelli F, Bogani G, Ditto A, et al. How often parametrial involvement leads to post-operative adjuvant treatment in locally advanced cervical cancer after neoadjuvant chemotherapy and type $\mathrm{C}$ radical hysterectomy? Eur J Surg Oncol. 2015;41(8):1089-1096.

30. Pol FJ, Zusterzeel PL, van Ham MA, Kuijpers DA, Bulten J, Massuger LF. Satellite lymphovascular space invasion: an independent risk factor in early stage cervical cancer. Gynecol Oncol. 2015;138(3): 579-584.

31. Perez-Andreu V, Roberts KG, Harvey RC, et al. Inherited GATA3 variants are associated with Ph-like childhood acute lymphoblastic leukemia and risk of relapse. Nat Genet. 2013;45(12):1494-1498.

32. Rachakonda SP, Penack O, Dietrich S, et al. Single-nucleotide polymorphisms within the thrombomodulin gene (THBD) predict mortality in patients with graft-versus-host disease. J Clin Oncol. 2014; 32(30):3421-3427.

33. Bogani G, Cromi A, Serati M, et al. Improving standard of care through introduction of laparoscopy for the surgical management of gynecological malignancies. Int J Gynecol Cancer. 2015;25(4):741-750.

34. Bogani G, Cromi A, Uccella S, et al. Laparoscopic versus open abdominal management of cervical cancer: long-term results from a propensity-matched analysis. J Minim Invasive Gynecol. 2014;21(5): 857-862.

35. Bogani G, Serati M, Nappi R, Cromi A, di Naro E, Ghezzi F. Nervesparing approach reduces sexual dysfunction in patients undergoing laparoscopic radical hysterectomy. J Sex Med. 2014;11(12): 3012-3020.

36. Bogani G, Cromi A, Serati M, et al. Predictors of postoperative morbidity after laparoscopic versus open radical hysterectomy plus external beam radiotherapy: a propensity-matched comparison. $J$ Surg Oncol. 2014;110(7):893-898.

37. Bogani G, Cromi A, Uccella S, et al. Nerve-sparing versus conventional laparoscopic radical hysterectomy: a minimum 12 months' follow-up study. Int J Gynecol Cancer. 2014;24(4):787-793.

38. Toptas T, Simsek T. Total laparoscopic versus open radical hysterectomy in stage IA2-IB1 cervical cancer: disease recurrence and survival comparison. J Laparoendosc Adv Surg Tech A. 2014;24(6):373-378.

39. Kong TW, Chang SJ, Lee J, Paek J, Ryu HS. Comparison of laparoscopic versus abdominal radical hysterectomy for FIGO stage IB and IIA cervical cancer with tumor diameter of $3 \mathrm{~cm}$ or greater. Int $J$ Gynecol Cancer. 2014;24(2):280-288. 


\section{Supplementary materials}

Table SI Factors associated with DFS in univariate analysis $(n=\mid 70)$

\begin{tabular}{|c|c|c|c|c|}
\hline \multirow[t]{2}{*}{ Variables } & \multirow[t]{2}{*}{ No of patients } & \multicolumn{3}{|l|}{ DFS } \\
\hline & & Five-year rate (\%) & HR & $P$-value \\
\hline \multicolumn{5}{|l|}{ Age at diagnosis (years) } \\
\hline$<35$ & 34 & 73.4 & I & \\
\hline $35-45$ & 82 & 65.3 & 1.26 & 0.57 \\
\hline$\geq 45$ & 54 & 57.6 & 2.00 & 0.09 \\
\hline \multicolumn{5}{|l|}{ Parity } \\
\hline$<2$ & 76 & 68.9 & 1 & \\
\hline$\geq 2$ & 85 & 62.3 & 1.34 & 0.31 \\
\hline Unknown & 9 & & & \\
\hline \multicolumn{5}{|l|}{ Histology } \\
\hline Squamous & 145 & 64.1 & I & \\
\hline Adenocarcinoma and adenosquamous & 25 & 70.4 & 0.95 & 0.89 \\
\hline \multicolumn{5}{|l|}{ Grade } \\
\hline 1 & 18 & 76.2 & $\mathrm{I}$ & \\
\hline 2 & 90 & 63.7 & 1.43 & 0.51 \\
\hline 3 & 62 & 64.8 & 1.89 & 0.24 \\
\hline \multicolumn{5}{|l|}{ Tumor size } \\
\hline$<4 \mathrm{~cm}$ & 122 & 66.0 & I & \\
\hline$\geq 4 \mathrm{~cm}$ & 48 & 62.5 & 1.31 & 0.36 \\
\hline \multicolumn{5}{|l|}{ Number of positive lymph nodes } \\
\hline$<3$ & 107 & 73.7 & I & \\
\hline$\geq 3$ & 63 & 49.6 & 1.85 & 0.02 \\
\hline \multicolumn{5}{|l|}{ Bilaterality of lymph node metastasis } \\
\hline Unilateral & 99 & 72.0 & I & \\
\hline Bilateral & 71 & 54.4 & 1.47 & 0.16 \\
\hline \multicolumn{5}{|l|}{ Common iliac lymph node metastasis } \\
\hline No & 145 & 70.3 & I & \\
\hline Yes & 25 & 35.6 & 3.19 & $<0.001$ \\
\hline \multicolumn{5}{|l|}{ FIGO stage } \\
\hline$|\mathrm{B}|$ & 76 & 74.4 & I & \\
\hline IB2 & 29 & 70.3 & 1.29 & 0.55 \\
\hline IIA & 49 & 53.6 & 2.07 & 0.02 \\
\hline IIB & 16 & 57.9 & 1.69 & 0.24 \\
\hline \multicolumn{5}{|l|}{ Lymph vascular space invasion } \\
\hline No & 124 & 74.4 & I & \\
\hline Yes & 46 & 55.1 & 1.71 & 0.055 \\
\hline \multicolumn{5}{|l|}{ Vaginal margin } \\
\hline Negative & 161 & 72.9 & 1 & \\
\hline Positive & 9 & 27.8 & 1.90 & 0.17 \\
\hline \multicolumn{5}{|l|}{ Parametrial infiltration } \\
\hline No & 152 & 73.8 & I & \\
\hline Yes & 18 & 37.0 & 2.76 & 0.002 \\
\hline \multicolumn{5}{|l|}{ Corpus invasion } \\
\hline No & 156 & 73.4 & I & \\
\hline Yes & 14 & 55.0 & 1.39 & 0.45 \\
\hline \multicolumn{5}{|l|}{ Deep stromal invasion } \\
\hline No & 72 & 70.3 & I & \\
\hline Yes & 98 & 60.4 & 1.61 & 0.10 \\
\hline
\end{tabular}

Abbreviations: DFS, disease-free survival; HR, hazards ratio; FIGO, Federation of Gynaecology and Obstetrics. 
Table S2 Factors associated with DFS in multivariate Cox regression before including the risk model as a covariate $(n=170)$

\begin{tabular}{lll}
\hline Variables & DFS & P-value \\
\cline { 3 - 3 } & HR & $<0.001$ \\
\hline Common iliac lymph node metastasis & $\mathrm{I}$ & \\
No & 3.18 & \\
Yes & & 0.002 \\
Parametrial infiltration & 1 \\
No & 2.74 \\
Yes
\end{tabular}

Abbreviations: DFS, disease-free survival; HR, hazards ratio.

Table S3 Performance of the population in different models for different risk groups

\begin{tabular}{|c|c|c|c|c|c|c|c|c|c|}
\hline Risk models & $\mathbf{n}$ & Five-year DFS & HR & $95 \% \mathrm{Cl}$ & $P$-value & Five-year OS & HR & $95 \% \mathrm{Cl}$ & $P$-value \\
\hline \multicolumn{10}{|l|}{ Alvarez et al' } \\
\hline Low & 8 & 100 & 0 & & & & 0 & & 0.98 \\
\hline Low-intermediate & 87 & 71.9 & I & & & 76.9 & I & & \\
\hline High-intermediate & 69 & 52.9 & 1.63 & $0.94-2.81$ & 0.08 & 63.1 & 1.68 & & 0.10 \\
\hline High & 6 & 50 & 2.27 & $0.68-7.55$ & 0.18 & 53.3 & 2.28 & & 0.27 \\
\hline \multicolumn{10}{|l|}{ Lai et $\mathrm{al}^{2}$} \\
\hline Low & 64 & 78.2 & 1 & & & 82.8 & I & & \\
\hline Intermediate & 62 & 62.4 & 1.70 & $0.85-3.42$ & 0.14 & 69.9 & 2.03 & $0.90-4.55$ & 0.09 \\
\hline High & 44 & 49.1 & 2.85 & $1.42-5.66$ & 0.003 & 58.3 & 3.28 & I.44-7.43 & 0.005 \\
\hline \multicolumn{10}{|l|}{ Samlal et $\mathrm{a}^{3}$} \\
\hline Low & 129 & 66.9 & 1 & & & 81.5 & I & & \\
\hline High & $4 I$ & 58.5 & 1.54 & $0.88-2.7 \mid$ & 0.13 & 56.7 & 1.89 & $0.99-3.52$ & 0.053 \\
\hline \multicolumn{10}{|l|}{ Aoki et $\mathrm{al}^{4}$} \\
\hline Low & 63 & 79.9 & 1 & & & 77.7 & I & & \\
\hline Intermediate & 92 & 60.2 & 2.03 & $1.05-3.94$ & 0.035 & 68.9 & 2.36 & $1.06-5.23$ & 0.035 \\
\hline High & 15 & 30 & 4.44 & $1.91-10.31$ & $<0.001$ & 34.6 & 6.10 & $2.35-15.84$ & $<0.001$ \\
\hline \multicolumn{10}{|l|}{ Park et $\mathrm{al}^{5}$} \\
\hline Low & 113 & 67.3 & 1 & & & 78.2 & I & & \\
\hline Intermediate & 57 & 60.1 & 1.58 & $0.93-2.69$ & 0.09 & 60.1 & 1.78 & $0.97-3.26$ & 0.06 \\
\hline High & 0 & & & & & & & & \\
\hline \multicolumn{10}{|l|}{ The present study } \\
\hline Low & $13 \mid$ & 73.7 & 1 & & & 81.9 & I & & \\
\hline Intermediate & 35 & 60.0 & 3.21 & $1.85-5.59$ & $<0.001$ & 42.8 & 3.04 & $1.6 \mathrm{I}-5.73$ & 0.001 \\
\hline High & 4 & 25.0 & 7.38 & $2.23-24.50$ & 0.001 & 25.0 & 14.52 & $4.15-50.88$ & $<0.001$ \\
\hline
\end{tabular}

Abbreviations: DFS, disease-free survival; HR, hazards ratio; OS, overall survival; $\mathrm{Cl}$, confidence interval.

Table S4 Prognostic models for early-stage cervical cancer treated with radical hysterectomy and pelvic lymph node dissection

\begin{tabular}{|c|c|c|c|c|c|c|c|c|c|}
\hline \multirow[t]{2}{*}{ References } & \multicolumn{3}{|c|}{ Characteristics } & \multicolumn{6}{|c|}{ Prognostic variables employed in the model } \\
\hline & $\mathbf{n}$ & Stage & Histology & TS & LVSI & PMI & $\begin{array}{l}\text { Number } \\
\text { of LNM }\end{array}$ & Histology & Others \\
\hline Alvarez et al' & 185 & IB-IIA & SCC & + & & & + & & \\
\hline Lai et $\mathrm{al}^{2}$ & 105 & IB-IIB & SCCIASC & & & + & + & & $\begin{array}{l}\text { DNA } \\
\text { index }\end{array}$ \\
\hline Samlal et $\mathrm{al}^{3}$ & 68 & IB-IIA & SCC/AC & & & + & & + & \\
\hline Aoki et al ${ }^{4}$ & 59 & IB-IIB & SCC/AC/ASC & & & + & + & & \\
\hline Park et $\mathrm{al}^{5}$ & 188 & IA2-IIA & SCC/AC/ASC & + & & + & & + & \\
\hline
\end{tabular}

Abbreviations: SCC, squamous carcinoma; AC, adenocarcinoma; ASC, adenosquamous carcinoma; TS, tumor size; LVSI, lymphatic/vascular space involvement; PMI, parametrial involvement; LNM, lymph node metastasis. 
